Monica Verdoia@, Orazio Viola, Giuseppina D’Amico, Cinzia Ravetto, Antonella Comoglio, Massimo Fusco, Paolo Giachino, Sara La Cognata, Francesca Novara@, Filippo Bristot, Pierpaolo Pipan, Morris Magnaghi, Pier Luigi Solda, Marta Brancatii , Marco Marcolongo

\title{
Advanced age, time to treatment and long-term mortality: single centre data from the FAST-STEMI network
}

\section{Corresponding author:}

Monica Verdoia, MD, PhD, Interventional Cardiologists and Research Fellow, Ospedale degli Infermi,

ASL Biella, Eastern Piedmont University, Via dei Ponderanesi, 13900 Biella, Italy, e-mail: monica.verdoia@asibi.piemonte.it

Medical Research Journal 2020; Volume 5, Number 3, 135-140 10.5603/MRJ.a2020.0015 Copyright (C) 2020 Via Medica ISSN 2451-2591

\begin{abstract}
Background. Optimization of the techniques and larger accessibility to mechanical reperfusion have significantly improved the outcomes of patients with ST-segment elevation myocardial infarction (STEMI). However, suboptimal results have been observed in certain higher-risk subsets of patients, as in advanced age, where the benefits of primary $\mathrm{PCl}$ are more debated. We evaluated the impact of systematic primary percutaneous coronary intervention (PCl) and an optimized STEMI network on the long-term prognosis from a single centre experience.

Methods. We included STEMI patients included in the FAST-STEMI network between 2016 and 2019. Ischemia duration was defined as the time from symptoms onset to coronary reopening (pain-to-balloon, PTB). The primary study endpoint (PE) was a composite of mortality and recurrent Ml at long-term follow-up. Indywidual outcome endpoints were also assessed.

Results. We included 253 patients undergoing primary $\mathrm{PCl}$ and discharged alive. Mean age was 67.2 \pm 12.5 years, $75.1 \%$ males and $19.8 \%$ diabetics.

At a median follow-up of 581 [307-922] days, the primary endpoint occurred in 24 patients (7.9\%), of whom $5.5 \%$ died.

The occurrence of a cardiovascular event was significantly associated with advanced age $(p<0.001)$, renal failure $(p=0.03)$, lower ejection fraction at discharge $(p=0.04)$ and longer in-hospital stay $(p=0.01)$. The median PTB was 198 minutes [IQR: 125-340 min], that was significantly longer among patients experiencing the PE $(p=0.01)$.

A linear relationship was observed between age and PTB $(r=0.13, p=0.009)$.

However, both age $\geq 75$ years and PTB above the median emerged as independent predictors of the primary endpoint (age: HR [95\% Cl] $=5.56$ [2.26-13.7], $p<0.001$, PTB: HR [95\%Cl] $=3.59$ [1.39-9.3], $p=0.01$ ). Similar results were observed for overall mortality.

Conclusion. The present study shows that among STEMI patients undergoing primary PCI in a single centre, the duration of ischemia and advance age are independently associated to long-term mortality and recurrent myocardial infarction. However, longer time to reperfusion was observed among elderly patients. Key words: ST-segment elevation myocardial infarction, primary percutaneous coronary intervention, hospital facility; ischemia time, outcome
\end{abstract}

Med Res J 2020; 5 (3): 135-140

\section{Background}

Prompt restoration of coronary perfusion represents the pivotal treatment for patients with ST-segment myocardial infarction (STEMI), allowing to improve myocardial salvage and prognosis [1-3]. Primary percutaneous coronary intervention $(\mathrm{PCl})$ has emerged in the last years as the strategy of choice for mechanical reperfu- sion, therefore great efforts have been accomplished for improving the techniques and facilitating the access of STEMI patients to coronary revascularization $[4,5]$.

The optimization of the networks for transportation and the larger availability of primary- $\mathrm{PCl}$ facilities, in particular, have shortened the time to reperfusion and contributed to enlarge the indications to primary $\mathrm{PCl}$ even to those higher-risk subsets of patients, as the 
elderly, that have been associated to an increased rate of complications and poorer outcomes [6-8]. Despite the role of a systematically invasive approach, rather than optimal medical therapy, has been largely debated among patients in advanced age or with severe comorbidities, several studies have confirmed the prognostic benefits of early primary $\mathrm{PCl}$ even in these settings $[9,10]$.

Nevertheless, the predictors of recurrent ischemic events, complications and long-term outcomes in elderly and more critical subsets of STEMI patients still need to be focused into additional dedicated studies.

Aim of the present study was to provide a single centre experience within an optimized STEMI network and a systematically invasive approach, attempting to define the predictors of the long term-prognosis among consecutive STEMI patients undergoing primary $\mathrm{PCl}$.

\section{Methods}

We analysed STEMI patients discharged alive after primary $\mathrm{PCl}$ in a non-academic public hospital from June 2016 to June 2019 and included in the FASTSTEMI database.

For all patients, demographical data, clinical features, cardiovascular risk factors and follow-up endpoints were derived from electronic medical reports.

Data regarding the time of symptoms onset, medical contact, transportation, primary $\mathrm{PCl}$, duration of hospitalization and ejection fraction at discharge were derived from the individual patients' worksheets enclosed in the FAST-STEMI system, (wwww.sistemapiemonte.it), a regional network for the optimization and monitoring of the management of patients with STEMI. Ischemia duration was defined as the time from symptoms onset to primary PCI (pain-to-balloon, PTB).

\section{Outcome endpoints}

The primary study endpoint (PE) was the occurrence of all-cause mortality or recurrent myocardial infarction at long-term follow-up. Secondary endpoints were the individual components of the primary endpoint or target vessel revascularization (TVR).

\section{Statistical analysis}

All statistical analyses were performed by SPSS Statistics Software 22.0 (IBM SPSS Inc., Chicago, Illinois). Continue variables were represented as mean $\pm S D$, while categorical variables as percentage. Chi-Squared and paired ANOVA test were appropriately used to com- pare continuous and categorical variables, respectively. In case of non-normal distribution median, IQR and non parametric U-test were applied. Linear regression analysis was applied to evaluate the relationship between continuous variables, as age and PTB.

Cox regression analysis and Kaplan-Meier survival curves were used to define the role of different variables on the PE. A p value $<0.05$ was considered statistically significant.

\section{Results}

We included 253 patients treated with primary $\mathrm{PCl}$ for STEMI and discharged alive.

Baseline characteristics of the included patients are displayed in Table 1. Mean age was $67.2 \pm 12.5$ years, $75.1 \%$ were males and $19.8 \%$ diabetics.

At a median follow-up of 581 [307-922] days, the primary endpoint occurred in 24 patients (7.9\%). The occurrence of a cardiovascular event was significantly associated with advanced age ( $p<0.001$ ), renal failure $(p=0.03)$, lower ejection fraction at discharge $(p=0.04)$ and longer in-hospital stay $(p=0.01)$, as in Table 1.

Mean times from symptoms onset to $\mathrm{PCl}$ are displayed in Table 2. In particular, PTB was significantly longer among patients experiencing the PE $(p=0.03)$ and also the percentage of patients with PTB above the median (198 minutes [IQR: 125-340 min]), (72.7\% vs $41.6 \%, p=0.006$, Fig. 1).

A linear relationship was observed between age and PTB $(r=0.13, p=0.009)$, as in Figure 2 .

However, both age $\geq 75$ years and PTB above the median emerged as independent predictors of the primary endpoint (age: $\mathrm{HR}[95 \% \mathrm{Cl}]=5.56$ [2.26-13.7], $p<0.001$, PTB: HR [95\%Cl] = 3.59 [1.39-9.3], $p=0.01$ ).

Kaplan Meier survival estimates in the overall population and according to age and ischemia duration are displayed in Figure 3.

Similar results were observed for the 14 patients (5.5\%) that died at follow-up. In fact age $\geq 75$ years and PTB above the median were confirmed as independent predictors of overall mortality (age: HR $[95 \% \mathrm{Cl}]=9.86[2.15-45.3], \mathrm{p}=0.003$, PTB: HR $[95 \% \mathrm{Cl}]=5.29[1.15-24.3], \mathrm{p}=0.03)$.

Recurrent myocardial infarction was observed among 11 patients (4.3\%) whereas 5 patients (2\%) underwent target vessel revascularization.

\section{Discussion}

The present manuscript provides a single centre experience on the prognostic predictors at long-term among STEMI patients treated in an updated network 
Table 1. Clinical and demographic characteristics in the overall population and according to primary endpoint (PE)

\begin{tabular}{|c|c|c|c|c|}
\hline Clinical features & $\begin{array}{c}\text { Overall } \\
(n=253)\end{array}$ & $\begin{array}{c}\text { PE } \\
(n=24)\end{array}$ & No PE (n = 229) & P Value \\
\hline Male gender (\%) & 75.1 & 66.7 & 76 & 0.32 \\
\hline Age (mean $\pm S D)$ & $67.2 \pm 12.5$ & $77.3 \pm 10$ & $66.1 \pm 12.3$ & $<0.001$ \\
\hline Age $\geq 85$ years $(\%)$ & 6.7 & 20.8 & 5.2 & 0.01 \\
\hline Age $\geq 75$ years $(\%)$ & 31.6 & 66.7 & 29.7 & $<0.001$ \\
\hline Diabetes mellitus (\%) & 19.8 & 16.7 & 20.1 & 0.99 \\
\hline Renal failure (\%) & 19.4 & 37.5 & 17.5 & 0.03 \\
\hline Transportation (\%) & & & & 0.36 \\
\hline Primary ambulance transportation & & 45.8 & 58.1 & \\
\hline Individual access & & 33.3 & 31.7 & \\
\hline Other & & 20.9 & 10.2 & \\
\hline Infarction location (\%) & & & & 0.77 \\
\hline Anterior & 49.4 & 55.6 & 48.8 & \\
\hline Inferior & 39.9 & 33.3 & 40.6 & \\
\hline Other & 10.7 & 11.1 & 10.6 & \\
\hline Ejection fraction at discharge (mean $\pm S D$ ) & $51.8 \pm 10.1$ & $47.7 \pm 13.5$ & $52.2 \pm 9.6$ & 0.04 \\
\hline
\end{tabular}

Table 2. Reperfusion timetable in the overall population and according to primary endpoint (PE)

\begin{tabular}{lcccc}
\hline $\begin{array}{l}\text { STEMI network timetable } \\
\text { (median [IQR]) }\end{array}$ & $\begin{array}{c}\text { Overall } \\
\mathbf{n = 2 5 3}\end{array}$ & $\begin{array}{c}\mathbf{P E} \\
\mathbf{( n = 2 4 )}\end{array}$ & $\begin{array}{c}\text { No PE } \\
\mathbf{( n = 2 2 9 )}\end{array}$ & P Value \\
\hline Pain to FMC (min) & $97[49-225]$ & $150[79-359]$ & $90[49-224]$ & 0.22 \\
First medical contact to door (min) & $54[36-90]$ & $72.5[39.5-128.8]$ & $53[36.5-87.5]$ & 0.49 \\
Pain to balloon (min) & $198[125-340]$ & $257.5[177.5-421.8]$ & $180[125-307]$ & 0.013 \\
Hospital stay (days) & $5[4-7]$ & $6[4-10.5]$ & $5[4-7]$ & 0.15 \\
\hline
\end{tabular}

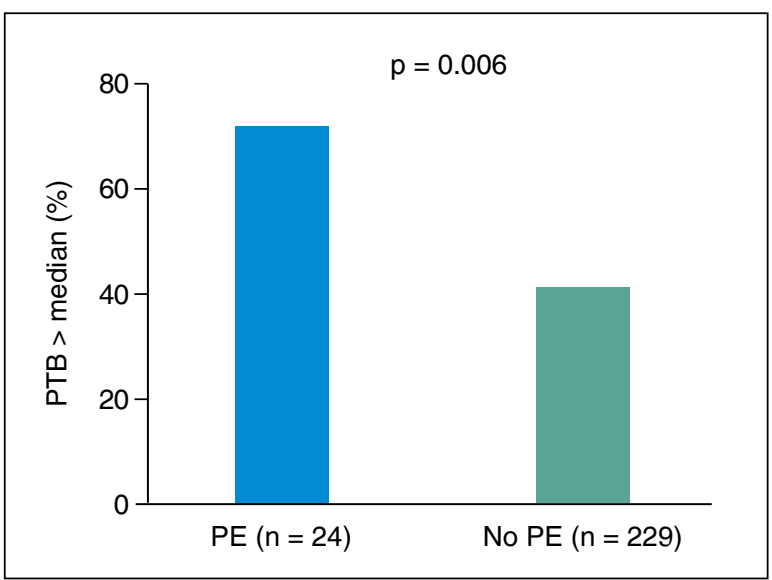

Figure 1. Bar graph showing the rate of patients with PTB above the median among event-free patients or experiencing the primary endpoint $(\mathrm{PE})$

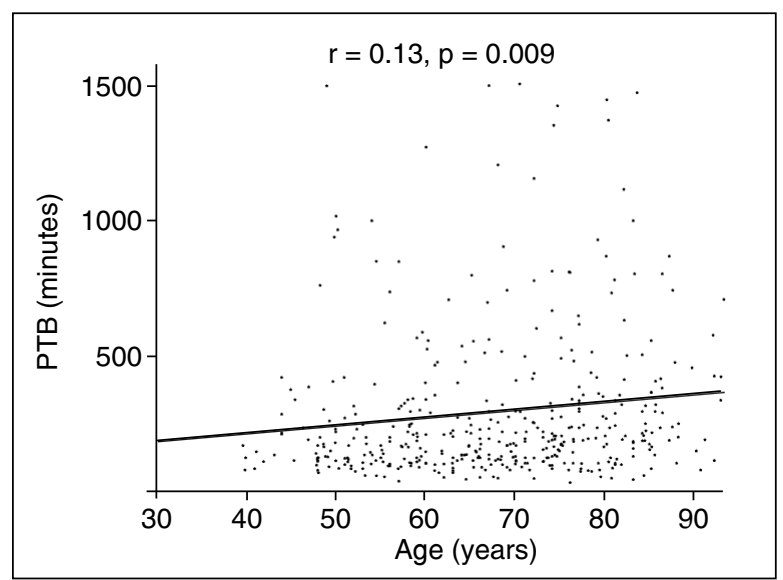

Figure 2. Linear relationship between age and pain to balloon (PTB) 


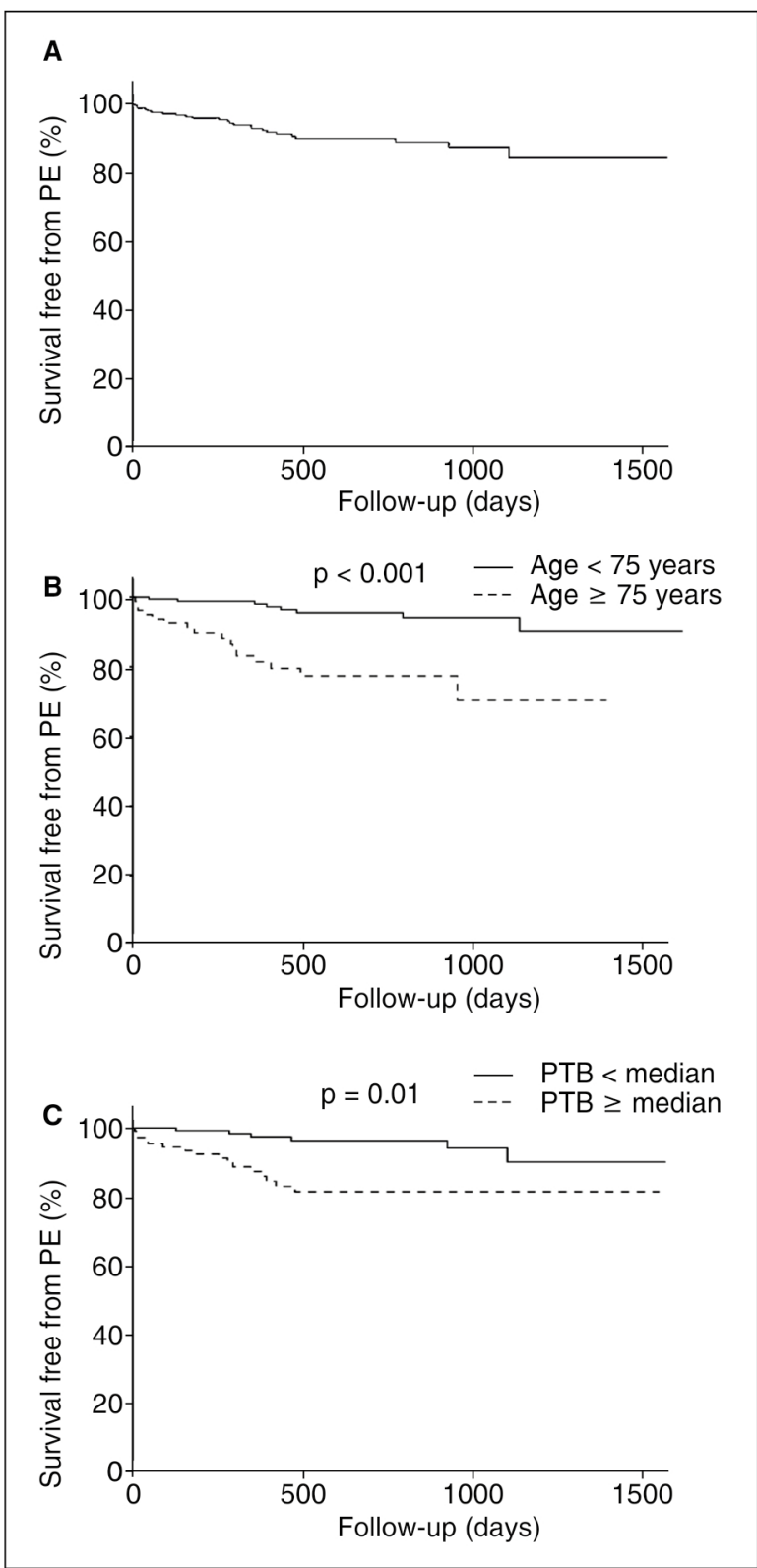

Figure 3. Kaplan Meier estimates for global survival in the overall population (3A) and according to age (3B) and pain to balloon (PTB) (3C)

and with systematic primary $\mathrm{PCl}$. We demonstrated that advanced age and the duration of ischemia represented the most relevant determinants of mortality and recurrent myocardial infarction, therefore emerging as the most challenging situations to be addressed in future studies.

Technological improvements and early reperfusion strategies have significantly contributed to increase the success of percutaneous coronary interventions (PCl) and ameliorated the outcomes of patients with acute myocardial infarction [11-13].
In addition, the introduction of more potent antithrombotic strategies have significantly lowered the rate of thrombotic complications and recurrent ischemic events [14, 15], although being weighted by a significantly increased risk of bleedings, and especially among those more fragile subsets of patients, as the elderly, that are, often prevented from aggressive revascularization strategies and newer antiplatelet agents for the fear of haemorrhagic complications [16].

Recent trials and registries specific for patients in advanced age presenting with acute coronary syndromes have documented the overall superiority of an early invasive approach over a conservative one [9, 10, 17].

Nevertheless, elderly patients still continue to display suboptimal treatment and a worse prognosis, and especially in the setting of STEMI, where advanced age has been associated to a more delayed presentation, unsuccessful reperfusion and larger infact size, conditioning survival and the risk of recurrent ischemic events $[18,19]$.

In fact, De Luca et al. have shown in a large cohort of over 1500 patients that advanced age was associated with a significantly higher clinical and angiographic risk profile, emerging as an independent predictor of 1-year mortality [20].

In addition, age and time to treatment have been related with a larger scintigraphic infact size, a parameter strictly associated with mortality, the duration of hospitalization and the risk of recurrent cardiovascular events [21, 22].

Large efforts have been accomplished so far in order to optimize the access of the patients to primary $\mathrm{PCl}$ facilities, including by the creation of joint networks, field in ambulance triage, for earlier activation of cathlab personnel and direct access of the patients without the emergency room passage [23-25].

In the Italian region of Piedmont, the FAST-STEMI network was created in 2011 in order to provide a geographical and logistic organization of the strategies for transferring patients with STEMI to primary- $\mathrm{PCI}$ capable hospital with the shortest transportation times. In-ambulance ECG and its telematic transmission, the creation of operations centres and data collection and monitoring through a unique web-based database represented the major point of the FAST-STEMI project [26].

We present the experience of a single centre from a non-academic public hospital enclosed in the FASTSTEMI network. We demonstrated a short time to reperfusion in our population as compared to the data from currently available literature, in line with the average reported at a regional and national level [27]. However, the patients experiencing the primary endpoint displayed a significantly longer duration of ischemia as compared to event-free patients, mainly driven by an almost double time from symptoms to diagnosis. 
Moreover, elderly patients experienced a longer time to treatment as compared to younger patients, however advanced age also emerged as an independent predictor of the long-term outcomes. Indeed, more atypical symptoms, delayed presentation and the assessment of concomitant or pre-existing medical conditions have been previously established to prevent a prompt access of these patients to primary $\mathrm{PCl}$.

In fact, in the National Registry of Myocardial infarction (NRMI), chest pain at presentation occurred in $89.9 \%$ of STEMI patients $<65$ years versus $56.8 \%$ of those $\geq 85$ years of age [28]. In the Global Registry of Acute Coronary Events (GRACE) registry, the median time from symptom onset to presentation was 2.3 hours in those under 45 years, but 3.0 hours over age 85 [29] and in the Cooperative Cardiovascular Project the predictors of late arrival ( $>6$ hours after symptom onset) included advanced age included advanced age and diabetes [30].

In our STEMI population, the time to reperfusion was shorter than in the GRACE registry [29] and older studies [31, 32], underlying the improvements provided by a dedicated optimized network. However, the duration of ischemia had a median of $>3$ hours, that was therefore superior to the 120 minutes recommended in guidelines and reported by Brodie et al. [33] as the cut-off for achieving an improvement in left ventricular ejection fraction $(6.9 \%$ at $<2 \mathrm{~h}$ vs $3.1 \%$ at $>$ or $=2 \mathrm{~h}$, $\mathrm{p}=0.007$ ), and in 30-days mortality.

Nevertheless, in a recent analysis from the large population based registry (ISACS-TC) consisting of 2,730 clinically stable patients with STEMI presenting 12-48 hours after symptom onset and treated with $\mathrm{PCl}$ or medical therapy, mortality benefits were observed among patients presenting $\geq 25-48$ hours after symptom onset, and especially for patients $\geq 65$ years old [34].

In addition, our definition of the primary endpoint also included recurrent myocardial infarction, that was associated with a higher patient's risk profile, although the lower number of events did not allow to perform an independent evaluation as an outcomes endpoint. In fact, previous studies have shown that rehospitalizations after $\mathrm{Ml}$ are most frequently attributed to bleeding (24.5\%), infections (14.3\%), and cancer $(9.1 \%)$, with age emerging as the main independent predictor of unplanned hospitalization [35].

However, Verdoia et al. also reported enhanced platelet reactivity and suboptimal response to antiplatelet drugs among patients in advanced age, potentially increasing the risk of stent thrombosis and recurrent ischemic events [36].

Therefore, further efforts should be accomplished in order to improve the management of patients admitted with STEMI, shortening the duration of ischemia and optimizing the reperfusion strategies and especially among those higher-risk subsets of patients as the elderly, where future dedicated studies are certainly warranted.

\section{Limitations}

A first limitation can be considered the small sample of patients included in our study, thus potentially affecting the statistical power of our study. However, our study represents a common scenario from a real life public hospital and furthermore, our results are in line with the conclusions reached in far larger cohorts of patients.

Another limitation can be considered the lack of certain information about clinical and procedural features and on pharmacological therapy at discharge. However, these data were not considered in the worksheets of the FAST-STEMI database, that represented the primary source of our analysis. Nevertheless, our population was managed according to the best standard of care in terms of drug-eluting stent technologies, dual antiplatelet therapy and medications, as statins and beta-blockers.

Finally, our data are derived from a single centre and limited to a quite elderly population in specific geographic environment, thus limiting the generability of our results.

\section{Conclusion}

The present study shows that among STEMI patients undergoing primary $\mathrm{PCl}$ in a single centre, the duration of ischemia and advance age are independently associated to long-term mortality and recurrent myocardial infarction. However, longer time to reperfusion was observed among elderly patients.

\section{References}

1. De Luca G, Suryapranata H, Ottervanger JP, et al. Time delay to treatment and mortality in primary angioplasty for acute myocardial infarction: every minute of delay counts. Circulation. 2004; 109(10): 1223-1225, doi: 10.1161/01.CIR.0000121424.76486.20, indexed in Pubmed: 15007008 .

2. De Luca G. [Treatment delayed is treatment denied! ]. Rev Esp Cardiol. 2009; 62(1): 1-6, indexed in Pubmed: 19150007.

3. De Luca G, Biondi-Zoccai G, Marino P. Transferring patients with ST-segment elevation myocardial infarction for mechanical reperfusion: a meta-regression analysis of randomized trials. Ann Emerg Med. 2008; 52(6): 665-676, doi: 10.1016/j.annemergmed.2008.08.033, indexed in Pubmed: 19027496.

4. De Luca G, Smits P, Hofma SH, et al. Drug-Eluting Stent in Primary Angioplasty (DESERT 3) cooperation. Everolimus eluting stent vs first generation drug-eluting stent in primary angioplasty: A pooled patient-level meta-analysis of randomized trials. Int J Cardiol. 2017; 244: 121-127, doi: 10.1016/j.ijcard.2017.06.022, indexed in Pubmed: 28673736

5. Task Fos, Steg PG, James SK, et al. et al.. ESC Guidelines for the management of acute myocardial infarction in patients presenting with ST-segment elevation. Eur Heart J 2012;33(20. ; 2569: 2619. 
6. Terkelsen CJ, Sørensen JT, Maeng M, et al. System delay and mortality among patients with STEMI treated with primary percutaneous coronary intervention. JAMA. 2010; 304(7): 763-771, doi 10.1001/jama.2010.1139, indexed in Pubmed: 20716739.

7. Postma S, Dambrink JHE, de Boer MJ, et al. The influence of residentia distance on time to treatment in ST-elevation myocardial infarction patients. Neth Heart J. 2014; 22(11): 513-519, doi: 10.1007/s12471 014-0599-8, indexed in Pubmed: 25273920.

8. De Luca L, Tomai F, Verdoia M, et al. Evaluation and management of special subgroups after primary percutaneous coronary intervention. Am Heart J. 2010; 160(6 Suppl): S22-S27, doi: 10.1016/i. ahj.2010.10.012, indexed in Pubmed: 21147288.

9. Puymirat E, Aissaoui N, Cayla G, et al. FAST-MI investigators. Changes in One-Year Mortality in Elderly Patients Admitted with Acute Myocardial Infarction in Relation with Early Management. Am J Med 2017; 130(5): 555-563, doi: 10.1016/j.amjmed.2016.12.005, indexed in Pubmed: 28065766

10. Morici N, Savonitto S, Ferri L, et al. Outcomes of Elderly Patients with ST-Elevation or Non-ST-Elevation Acute Coronary Syndrome Undergoing Percutaneous Coronary Intervention. The American Journal of Medicine. 2019; 132(2): 209-216, doi: 10.1016/i.amimed.2018.10.027.

11. De Luca G, Verdoia M, Cassetti E. Thrombectomy during primary angioplasty: methods, devices, and clinical trial data. Curr Cardio Rep. 2010; 12(5): 422-428, doi: 10.1007/s11886-010-0133-6, indexed in Pubmed: 20645031

12. Nardin M, Verdoia M, Barbieri L, et al. Radial vs Femoral Approach in Acute Coronary Syndromes: A Meta- Analysis of Randomized Trials. Curr Vasc Pharmacol. 2017; 16(1): 79-92, doi: 10.2174/15701 61115666170504125831, indexed in Pubmed: 28490313

13. De Luca G, Marino P. Advances in antithrombotic therapy as adjunct to reperfusion therapies for ST-segment elevation myocardial infarction. Thromb Haemost. 2008; 100(2): 184-195, indexed in Pubmed 18690336.

14. Verdoia M, Kedhi E, Suryapranata $H$, et al. Benefits of short-term or prolonged as compared to standard 1 year DAPT in patients with acute coronary syndrome treated with drug-eluting stents: a meta-analysis of 9 randomized trials. J Thromb Thrombolysis. 2020 [Epub ahead of print] doi: 10.1007/s11239-019-02033-2, indexed in Pubmed: 31919736.

15. Verdoia M, Schaffer A, Barbieri L, et al. Benefits from new ADP antagonists as compared with clopidogrel in patients with stable angina or acute coronary syndrome undergoing invasive management: a meta-analysis of randomized trials. J Cardiovasc Pharmacol. 2014 63(4): 339-350, doi: 10.1097/FJC.0000000000000052, indexed in Pubmed: 24336016.

16. Andreotti F, Rocca B, Husted S, et al. ESC Thrombosis Working Group. Antithrombotic therapy in the elderly: expert position paper of the European Society of Cardiology Working Group on Thrombosis. Eur Heart J. 2015; 36(46): 3238-3249, doi: 10.1093/eurheartj/ehv304, indexed in Pubmed: 26163482.

17. De Luca L, Marini M, Gonzini L et al Contemporary Trends and Age-Specific Sex Differences in Management and Outcome for Patients With ST-Segment Elevation Myocardial Infarction. J Am Heart Assoc. 2016; 5(12), doi: 10.1161/JAHA.116.004202, indexed in Pubmed 27881426

18. De Luca G, Dirksen MT, Spaulding C, et al. DESERT cooperation Impact of age on long-term outcome after primary angioplasty with bare-metal or drug-eluting stent (from the DESERT cooperation). Am J Cardiol. 2013; 112(2): 181-186, doi: 10.1016/j. amjcard.2013.03.012, indexed in Pubmed: 23664294

19. Luca GDe, Hof Av, Huber K, et al. Impact of advanced age on myocardial perfusion, distal embolization, and mortality patients with ST-segment elevation myocardial infarction treated by primary angioplasty and glycoprotein IIb-IIla inhibitors. Heart and Vessels. 2013; 29(1) 15-20, doi: 10.1007/s00380-013-0323-4.

20. De Luca G, van 't Hof AWJ, Ottervanger JP, et al. Ageing, impaired myocardial perfusion, and mortality in patients with ST-segment elevation myocardial infarction treated by primary angioplasty. Eur Heart J. 2005; 26(7): 662-666, doi: 10.1093/eurheartj/ehi110, indexed in Pubmed: 15681574

21. De Luca G, Parodi G, Sciagrà R, et al. Preprocedural TIMI flow and infarct size in STEMI undergoing primary angioplasty. J Thromb Thrombolysis. 2014; 38(1): 81-86, doi: 10.1007/s11239-013-0977-x, indexed in Pubmed: 23928869.
22. Selker HP, Udelson JE, Ruthazer R, et al. Relationship between therapeutic effects on infarct size in acute myocardial infarction and therapeutic effects on 1-year outcomes: A patient-level analysis of randomized clinical trials. Am Heart J. 2017; 188: 18-25, doi: 10.1016/j. ahj.2017.02.028, indexed in Pubmed: 28577674.

23. Fosbøl EL, Granger CB, Peterson ED, et al. Prehospital system delay in ST-segment elevation myocardial infarction care: a novel linkage of emergency medicine services and in hospital registry data. Am Heart J. 2013; 165(3): 363-370, doi: 10.1016/j.ahj.2012.11.003, indexed in Pubmed: 23453105

24. Wöhrle J, Desaga M, Metzger C, et al. Impact of transfer for primary percutaneous coronary intervention on survival and clinical outcomes (from the HORIZONS-AMI Trial). Am J Cardiol. 2010; 106(9): 1218-1224, doi: 10.1016/j. amjcard.2010.06.049, indexed in Pubmed: 21029816

25. Postma S, Kolkman E, Rubinstein SM, et al. Field triage in the ambulance versus referral via non-percutaneous coronary intervention centre in ST-elevation myocardial infarction patients undergoing primary percutaneous coronary intervention: A systematic review. Eur Heart J Acute Cardiovasc Care. 2017; 6(5): 396-403, doi: 10.1177/2048872615600098, indexed in Pubmed: 26273071.

26. https://www.regione. piemonte.it/web/sites/default/files/media/documenti/2019-02/report_fast_stemi_2013.pdf.

27. Casella G Ottani F Ortolani P et al Off-hour primary percutaneous coronary angioplasty does not affect outcome of patients with ST-Segment elevation acute myocardial infarction treated within a regional network for reperfusion: The REAL (Registro Regionale Angioplastiche dell'Emilia-Romagna) registry. JACC Cardiovasc Interv. 2011; 4(3): 270-278, doi: 10.1016/j.jcin.2010.11.012, indexed in Pubmed: 21435603.

28. Rogers WJ, Bowlby LJ, Chandra NC, et al. Treatment of myocardial infarction in the United States (1990 to 1993). Observations from the National Registry of Myocardial Infarction. Circulation. 1994; 90(4): 2103-2114, doi: 10.1161/01.cir.90.4.2103.

29. Avezum A, Makdisse M, Spencer F, et al. GRACE Investigators. Impact of age on management and outcome of acute coronary syndrome: observations from the Global Registry of Acute Coronary Events (GRACE). Am Heart J. 2005; 149(1): 67-73, doi: 10.1016/j.ahj.2004.06.003, indexed in Pubmed: 15660036.

30. Saczynski JS, Yarzebski J, Lessard D, et al. Trends in prehospital delay in patients with acute myocardial infarction (from the Worcester Heart Attack Study). Am J Cardiol. 2008; 102(12): 1589-1594, doi: 10.1016/j. amjcard.2008.07.056, indexed in Pubmed: 19064010.

31. Birkemeyer R, Rillig A, Koch A, et al. Primary angioplasty for any patient with ST-elevation myocardial infarction? Guideline-adherent feasibility and impact on mortality in a rural infarction network. Clin Res Cardiol. 2010: 99(12): 833-840, doi: 10.1007/s00392-010-0196-9, indexed in Pubmed: 20607543

32. Steffenino G, Chinaglia A, Millesimo G, et al. PRIMA Investigators. Management of acute ST-elevation myocardial infarction in the coronary care units of Piedmont in 2005: results from the PRIMA regionwide survey. J Cardiovasc Med (Hagerstown). 2008; 9(2): 169-177, doi: 10.2459/JCM.0b013e3281ac210c, indexed in Pubmed: 18192810.

33. Brodie BR, Stuckey TD, Hansen CJ, et al. Effect of treatment delay on outcomes in patients with acute myocardial infarction transferred from community hospitals for primary percutaneous coronary intervention. Am J Cardiol 2002: 89(11): 1243-1247, doi: $10.1016 / \mathrm{s} 0002$ 9149(02)02319-6, indexed in Pubmed: 12031721.

34. Bugiardini R, Cenko E, Yoon J, et al. LATE PCI IN STEMI: A COMPLEX NTERACTION BETWEEN DELAY AND AGE. Journal of the American College of Cardiology. 2018; 71(11): A44, doi: 10.1016/s07351097(18)30585-0.

35. Spitzer E, Frei M, Zaugg S, et al. Rehospitalizations Following Primary Percutaneous Coronary Intervention in Patients With ST-Elevation Myocardial Infarction: Results From a Multi-Center Randomized Trial. J Am Heart Assoc. 2017; 6(8), doi: 10.1161/JAHA.117.005926, indexed in Pubmed: 28780509.

36. Verdoia M, Pergolini P, Nardin M, et al. Novara Atherosclerosis Study Group (NAS), Novara Atherosclerosis Study Group (NAS), Novara Atherosclerosis Study Group (NAS). Advanced age and high-residual platelet reactivity in patients receiving dual antiplatelet therapy with clopidogrel or ticagrelor. J Thromb Haemost. 2016; 14(1): 57-64, doi: 10.1111/jth.13177, indexed in Pubmed: 26512550. 